\title{
POLICY INSIGHTS
}

\section{Inter-regional development in China: An assessment}

\author{
Sarah Chan
}

East Asian Institute, National University of Singapore, Singapore

\begin{abstract}
China's regional planning and development has been a key national priority since the start of economic reform and opening up. China's regional development strategy has constantly evolved and has shifted to prioritizing integrated areas and mega-clusters to promote internal connectivity, increase urbanization and employment, and consequently, domestic consumption. This is distinct from past regional rebalancing initiatives, which were mainly aimed at reducing regional income gaps and relieving pressure from population flows to developed coastal regions. To support regional integration and sustain economic growth, institutional or structural policies to remove factor market distortions are just as necessary as increased investment in physical infrastructure, given that China's domestic market is huge but highly fragmented. As China faces rising external geopolitical and global economic uncertainties, its regional development strategy will be to emphasize more on "dual circulation" to boost domestic demand and strengthen China's supply chain resiliency, while still enhancing trade linkages with global markets to spur competition and support its industrial upgrading efforts.
\end{abstract}

Keywords: regional development; integration; urban; infrastructure

\section{Introduction}

A salient feature in the economic development of China has been the important role that foreign trade plays in driving its economic growth, which has expanded rapidly on account of liberalized trade and investment after its WTO accession in 2001. Since 2010, China's GDP growth has slowed, both structurally and cyclically. Reflecting its economic transition, China's growth deceleration was evident in its gradual rebalancing of the economy from export- and investmentdriven growth to a service-focused, domestic-demand-driven model. Cyclically, China's growth had been impacted by the slowing of the global economy and tepid world growth, fueled in part by antiglobalization sentiments. The US-China trade war and the Covid pandemic particularly highlighted China's over-reliance on foreign resources and technological know-how, prompting China to deploy a "dual circulation" strategy to shield itself from external geopolitical and global economic uncertainties.

This dual circulation growth strategy, endorsed by the Decisions of the $5^{\text {th }}$ Plenum of the $19^{\text {th }}$ Central Committee of the Communist
ARTICLE INFO

Received: April 6, 2021

Accepted: June 10, 2021

Available online: June 29, 2021

*CORRESPONDING AUTHOR Sarah Chan, 469 Bukit Timah Road, \#04-08, Tower Block, 259770 Singapore eaicsfs@nus.edu.sg

CITATION

Chan S (2021). "Inter-regional development in China: An assessment". Journal of Infrastructure, Policy and Development, 5(1): 1270. doi: $10.24294 /$ jipd.v5i1.1270

COPYRIGHT

Copyright (C) 2021 by author(s) and EnPress Publisher LLC. This work is licensed under the Creative Commons Attribution-NonCommercial 4.0 International License (CC BY-NC 4.0). http://creativecommons.org/licenses/ by $/ 4.0 /$ 
Party of China in October 2020, aims to boost the strength and resilience of China's domestic economy, while enhancing China's trade linkages with the world. Promoting regionally coordinated development thereby forms a significant part of this dual circulation development paradigm, since China's differentiated regional policy and idiosyncratic geographical factors have led to unbalanced development in various regions, posing a major threat to the sustainability of China's domestic economy.

Promoting integrated development among Chinese cities to create city or region clusters will require new investment in infrastructure to stimulate domestic consumption. Investment in physical infrastructure is key to improving connectivity among cities, facilitating factor mobility and supporting regional integration. The government is also planning to invest in new infrastructures, such as high-capacity fiber-optic networks, and improve digital connectivity in medium and small cities in the western and central areas. However, upgrading or making new investments in traditional and new infrastructure is not the only prerequisite for China's regional development. Policies to address capital immobility or distorted factor markets, such as labor, land and capital, are often crucial in spurring productivity growth and regional development. With factor misallocation, the urban agglomeration effect, which refers to the spatial concentration of economic activities in cities, could not be highly effective. Urban agglomeration effect can have a positive effect on economic growth and development via faster productivity growth arising from higher geographical concentration (due to urbanization and urban concentration). Urban concentration (i.e., clustering of people and industries) enhances economies of scale in the provision of urban infrastructure and public services, thereby creating positive spillovers on growth (Henderson, 2003). In China, markets are highly fragmented and many local governments are incentivized to implement local industrial policies to generate more tax revenue and local growth. As such, they may create entry barriers, which will segmentalize the market, by giving priority to industries that are associated with high investment and output. The Yangtze River Delta, for instance, suffered from misallocation of capital as a result of the local industrial policy. For example, about half of the cities in the region listed metallurgical and petrochemical industries, which could dramatically promote GDP and investment, as a priority for industrial development in their $13^{\text {th }}$ Five-Year Plan (2016-2020). This had reduced the efficiency of the allocation of capital across localities. Coordinated policies among the different local governments in various cities or provinces to facilitate collaboration are hence necessary to support regional integration and economic growth.

This paper is structured as follows. The first section examines the evolution of regional planning and development strategies in China for the past few decades, while the second section analyzes the regional patterns in growth and recent trends in regional economic development under China's dual circulation. The third section discusses the challenges and pertinent issues facing various regions, underscoring the importance of institutional policies (i.e., aspects of soft infrastructure), while the last section concludes.

\section{Evolution of regional development strategies}

China's regional planning and development has been a key national priority since the start of economic reform and opening up. The development of regions has undergone various phases and is constantly evolving in light of past policies and the challenges that have arisen. When the reform 
and opening up saw an accumulation of wealth in the eastern coastal areas with the establishment of the special economic zones, policies were put in place to accelerate the development of the central and western regions after 1978. ${ }^{1}$ The Western Development Strategy implemented in 1999 was such a response that involved large-scale infrastructure projects and industrial upgrading to resolve regional disparities and imbalances. Following this was the strategy of the revitalization of old northeast industrial bases adopted in 2003 to restructure and upgrade technological capabilities and reduce pollution.

China's coordinated development strategy comprises policies to support the development of central China, such as building an integrated transport system and an energy and strategic resource base, expanding markets and strengthening manufacturing and technology industries. The focus in the past was on further improving resource efficiency and enhancing sustainable development in the eastern coastal areas, which had earlier spearheaded the country's economic development. With reversing demographic dividends, as well as over-investment and lower productivity, measures were taken to accelerate state-owned enterprise (SOE) reform ${ }^{2}$ and increase innovation capabilities to achieve allocative efficiency and shift from capital-driven and resource-driven growth to innovationdriven growth.

Overall, the four key regional strategies of Western Region Development, Northeast Region Revitalization, Rise of the Central Region and Leading Development in the Coastal Region aim to cultivate new growth poles to unlock untapped economic potential, facilitate the exploitation of a region's potential advantages and promote regional competitiveness. Since China's 18th Party Congress in 2012, three major regional strategies, namely, the Belt and Road Initiative (BRI), ${ }^{3}$ Jing-Jin-Ji (Beijing-Tianjin-Hebei) Coordinated Development and Yangtze River Economic Belt (YREB), ${ }^{4}$ have been proposed to complement the aforementioned four strategies. Apart from the similar aim of developing new growth areas, these strategies (initiatives) also focus on increasing efficiency in the spatial allocation of production factors and enhancing regional specialization. By leveraging on the potential of agglomeration economies that arise from the cost savings in transport/ communication and from close, intense economic interaction as firms and infrastructure operate at scale, regional specialization is expected to improve economic welfare and growth.

\footnotetext{
1. The east remains China's economic locomotive. Although its provincial economies had grown more slowly than those in the central and western regions for most of the past decade from 2005 to $2015-9 \%$ on average compared to $9.8 \%$ and $10.5 \%$, respectively, for the central and western regions - the 10 eastern provinces make up more than half of China's GDP despite being home to just over a third of its population. The eastern region encompasses Beijing and all of China's eastern coastal provinces with the exception of Liaoning, which covers a small stretch of China's coast just north of Hebei. Together, the east's 10 provinces rank as the world's third-largest economy, behind only the United States and China itself. The east includes Beijing, Fujian, Guangdong, Hainan, Hebei, Jiangsu, Shandong, Shanghai, Tianjin and Zhejiang. Central China includes Anhui, Hubei, Henan, Hunan, Jiangxi and Shanxi. The west encompasses Chongqing, Gansu, Guangxi, Guizhou, Inner Mongolia, Ningxia, Qinghai, Shaanxi, Sichuan, Tibet, Xinjiang and Yunnan. Northeast includes Heilongjiang, Jilin and Liaoning.
}

2. As part of the SOE reform, the authorities categorized SOEs into commercial SOEs and public-interest SOEs, depending on the degree of their commercial orientation. For commercial-competitive SOEs, as opposed to commercial-strategic firms, the priority is to expose them to market competition and reduce government interference that goes beyond its shareholder role. Another strategy is to strengthen corporate governance by expanding "mixed ownership" reforms to further increase non-state equity in SOEs so as to improve corporate governance and performance.

3. The BRI aims to jump-start economies of the central and western regions of China through increased exports to neighboring countries, such as Kazakhstan, Myanmar and Pakistan.

4. As evidence of this, the August 2019 meeting of China's Central Economic and Financial Affairs Commission, the country's highest economic policymaking body, specifically mentioned that "hub cities and city clusters are becoming the main medium for growth and development" and that policies should enhance the economic and population capacity of these regions to facilitate the agglomeration of productive factors. This marked the first time in many years that policymakers emphasized the role of large city clusters in advanced regions (Morgan Stanley, 2019). 
The clustering of economic activities by way of regional specialization has accelerated the pace of growth and development. Market forces have pushed China towards concentrating industry in its large metropolitan areas, with the Yangtze River Delta and Pearl River Delta emerging as dominant industrial hubs. However, the locations of economic activity have been changing over the past decade. According to a World Bank report, the eastern region (particularly provincial capitals) has seen a decline in manufacturing employment growth, while the reverse is prevalent in prefecturelevel cities in the central region (World Bank and the PRC's Development Research Centre of the State Council, 2020). Evidently, the geographic center of manufacturing firms has been moving from the east towards the center of China since 2008 (World Bank and the PRC's Development Research Centre of the State Council, 2020). While the growth of manufacturing slowed in large cities and metropolitan areas in the east, innovative activities have begun to concentrate in the coastal region's largest metropolitan areas. For instance, Guangdong contributed 19.3\% of total patents granted in 2017, the largest among provinces, followed by Jiangsu and Zhejiang. Shenzhen, after years of being a manufacturing center for electronics, is now home to some of China's dynamic private firms, such as Huawei, ZTE and Tencent. These firms are investing in research and development (R\&D) and developing innovations that can take advantage of technology trends in artificial intelligence, cloud computing, mobile software and the Internet of Things.

On the contrary, provinces in the central and western regions are among the least innovative and laggards in economic performance despite several rounds of regional revival efforts. Although some interior locations, such as Sichuan's capital, Chengdu, and the province Chongqing, have started to gain ground in attracting notable clusters of high-tech firms, most export-oriented high-technology industries remain concentrated in China's coastal areas. Innovation capacity is still highest in China's most developed regions (Figure 1). Driven by talent and capital, the more developed areas have attracted and retained innovation giants and technology companies strong in R\&D. For instance, Beijing, Shanghai and Shenzhen are home to $60 \%$ of the top 100 internet companies

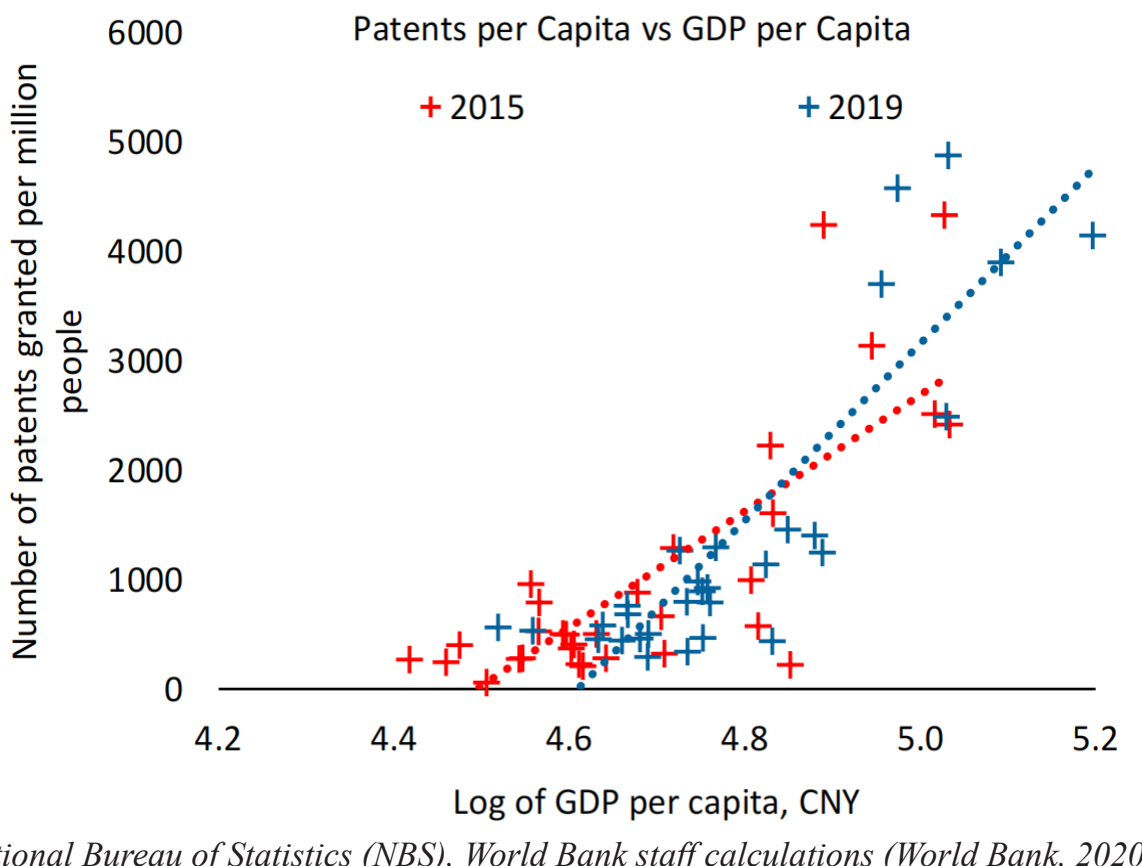

Source: China National Bureau of Statistics (NBS), World Bank staff calculations (World Bank, 2020)

Figure 1. The geography of ideas - Innovation capacity is higher in richer provinces. 
in China, with 22\% located in Beijing, which allows firms to leverage its higher educational institutes and scientific research bodies (Deloitte, 2019). Government policies (such as taxation and investment) have also driven innovation activity in cities such as Guangzhou. In 2017, the Guangzhou municipal government began to promote the next-generation information technology, artificial intelligence and biomedical strategy, which aims to upgrade the manufacturing industry (Deloitte, 2019).

In contrast, the innovation infrastructure and investment in less developed cities, such as Hefei, Nanjing or Guiyang, are hampered by the level of economic development and scale of the local economy. A coordinated and integrated approach is thus needed to lift the relatively less developed regions out of stagnation, with market-oriented reforms to improve the local economy and policies to help the regions diversify into new sectors/industries.

\section{Regional trends in China's provinces}

\subsection{Patterns in regional economic development}

China is a rare, continental-sized economy with huge diversity that can contain the evolution of comparative advantage within its own borders (Wong, 2016). The more developed coastal regions have been transferring their declining comparative advantage in labor-intensive products to the less developed inland and central areas, while moving up the industrial value chain and into services. The central provinces of Henan and Anhui (which sit adjacent to China's eastern provinces and boast shorter transportation times to east coast ports relative to other central provinces and the west) were the first to attract manufacturers. Manufacturing investment also poured into the western provinces of Sichuan and Chongqing, with the latter now counting as China's largest manufacturer of laptop computers and factories in Sichuan among China's largest producers of microchips.

The economic drivers that anchor China's provincial economies are as diverse across the various regions as they are within. While the coastal economies in the east were the first to benefit from China's opening up to global trade, which was underpinned by foreign direct investment (FDI) liberalization policies, two key drivers had revved up growth in China's interior. First, manufacturers' search for cheaper labor had propelled investment in factories inland and, second, the global commodities boom (i.e., near tripling of global oil prices from 2005 to mid-2014) had channeled investment into the resource-rich interior. More recently, some central and western provinces have attracted investment in high-tech manufacturing via the Made in China 2025 initiative aimed at raising the domestic content of products and alleviating import dependence by strengthening domestic manufacturing capabilities in key industries such as information technology and new energy. For instance, microchip manufacturers in Chengdu have been among the largest recipients of government subsidies, while electric carmakers in Hangzhou and Xi' an are at the center of China's push to develop driverless vehicles (Moody's Analytics, 2019). Meanwhile, efforts to improve overland and maritime trade and transport links with South and Southeast Asia serve as growth drivers for China's southwestern provinces, such as Guangxi, Guizhou and Yunnan.

Driven by faster growth in the coastal region, regional incomes had initially diverged, with the coastal region receiving a disproportionate share of the government's capital investment (53\% versus $25 \%$ and $21 \%$ to the central and western regions, respectively) between 1999 to 2005 (World 


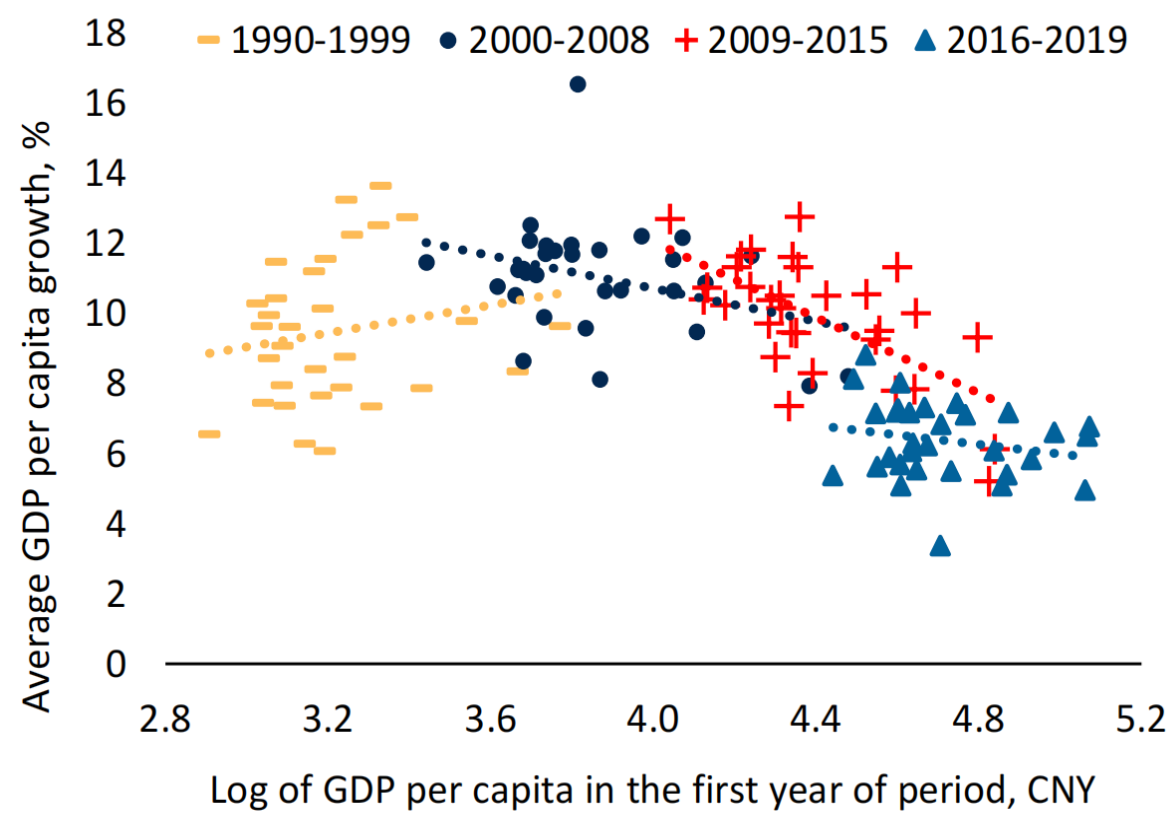

Source: NBS, World Bank staff calculations (World Bank, 2020)

Figure 2. Lagging provinces catching up.

Bank, 2020). However, this trend has reversed since the mid-2000s when China experienced a process of gradual regional convergence. Regional disparities have trended downwards, with the central and western regions gradually closing the per capita GDP gap with the wealthier eastern region (Figure 2). Growth in output, income and wages, however, did not extend to the northeast, which suffered from economic stagnation. Although the northeastern provinces were among the first to industrialize and the focal point of state-led industrialization efforts in the 1960s and 1970s, growth has slowed from the mid-2000s due to their reliance on heavy industry. ${ }^{5}$ Being important steel-making centers, the northeast regions have been especially sensitive to local producers' efforts to curtail supply amid a global steel glut and stricter pollution controls.

While China's inland provinces have made some strides in narrowing the gaps in output, income and wages with the more developed eastern coastal regions (Moody's Analytics, 2019), slower growth in global commodity prices and the emergence of lower-cost manufacturing clusters in Southeast Asia will be challenges for China's inland provinces, making future output and productivity gains harder to come by. Given the neighboring economies' comparative advantage in cheaper labor, China has already ceded some of its global market share in textiles and apparel to Indonesia, for instance. Vietnam is also emerging as a prominent newcomer in the regional supply chains, with South Korea increasing its investment in Vietnam's electronics industry, such as memory chips typically used in smartphones. China's advantage in manufacturing production could be affected if Southeast Asian economies climb the value-added chain and divert foreign investment from China.

The rise of high-tech industries and services in China's coastal provinces will widen the

5. Economic growth in the northeast region averaged $8 \%$ in the decade from 1995 but was an estimated $11.8 \%$ from 2005 to 2010 before subsequently slowing to approximately 5\%-6\% from 2010 to 2019 . 
economic gap with the less developed regions, even if external demand and global trade slow. Research and development spending is heavily concentrated in the east, with the provinces of Jiangsu and Guangdong accounting for two-thirds of total resident patent applications in China (Moody's Analytics, 2019). Similarly, the number of patents in force that originated from the eastern provinces comprises more than two-thirds of the national total (Moody's Analytics, 2019). Provincial economies with thriving high-tech service industries are generally expected to experience larger gains in productivity than resource-driven economies inland. The east, where these industries are concentrated, will shape the contours of growth at the national level and play a bigger role in driving productivity and overall economic growth.

Given the clustering of high-value manufacturing industries in the east, difficulties in gaining access to leading technologies due to US-China geopolitical tensions could be a headwind despite China's rapid ascent in the tech value chain. Technological restrictions imposed by the United States would adversely affect some IT sectors in China, as the latter is still a net importer of certain electronics components, such as semiconductor devices. Although China is rapidly developing local innovation capacity, it is dependent on core imported technology (Chan, 2020). For instance, in the electric vehicles industry, while domestic companies largely produce major components such as batteries, China still relies on foreign supplies for core components, such as microcontroller units and insulated gate bipolar transistor-based power modules (McKinsey Global Institute, 2019). China's bid for technological self-sufficiency may face challenges given its deep integration with global supply chains and years of benefiting from technology transfers via foreign direct investment. This will have implications on China's regional growth and development.

Simmering trade tensions between the United States and China represent the greatest challenge and risk to the outlook of China's regions. Should the US-China trade and technology conflict escalate, the hit to global demand would deal a setback to the economic growth across China's provinces. Some segments of the supply chain would relocate from China, though the dominance of the services sectors in the east would largely insulate these regions from industrial disruption. While northeast China (Jilin, Heilongjiang, Liaoning) would be the least affected given its limited exposure to global trade, it will continue to face issues relating to demographic aging (i.e., falling workingage population owing to emigration and low birth rates) and slow pace of SOE reform. Furthermore, the heavy industrial nature of Northeast China meant that job opportunities for young graduates are limited, negatively impacting the long-term economic potential of the region as a result of brain drain and inadequate talent/labor. The absence of clean local institutions has clearly also inhibited economic activities, posing relatively high transaction costs and leading to widespread rent-seeking practices for investors.

\subsection{Regional development in China under dual circulation strategy}

China's technology war with the United States has aggravated concerns over supply chain reliance. As US-China trade tensions and the COVID-19 pandemic have reshuffled some supply chains away from China, China's leaders have been promoting a "dual circulation" growth model as its new economic and social development plan. While no concrete details have been provided on the strategy, the key message has been interpreted as a strategic focus on strengthening self-sufficiency, deepening efforts to open up the economy and improving China's economic resilience. The new development pattern will focus on "domestic circulation" to boost domestic demand, address weak 
links in the supply system (with supply-side structural reforms) and strengthen China's supply chain resiliency. It also aims to reduce China's reliance on overseas markets and foreign suppliers in key areas, such as high-end technology and natural resources (HSBC, 2020a). This is to better position China in the long run to withstand global uncertainty and adapt to an increasingly hostile external environment characterized by a slowing global economy, rising protectionism, heightening geopolitical tensions and a shrinking international market.

In line with the "dual circulation development" strategy, policies will be targeted towards enhancing trade linkages with global markets to support China's industrial upgrading, as well as to strengthen domestic demand. China has a large and robust industrial ecosystem, strong manufacturing production capacity, highly educated and skilled workforce, well-developed infrastructure and a huge domestic market with a rapidly urbanizing middle-income class. To unlock the domestic potential and boost China's international competitiveness, further industrial upgrading and investment in basic and smart infrastructure, as well as a new urbanization strategy (focusing on developing city clusters and metropolitan areas), are required to support a domestic demand-oriented development model. To a large extent, these policies are largely a continuation of the government's stated goals a decade ago. Expanding domestic demand and supply-side reforms are some of the strategies implemented since the 2008 Global Financial Crisis to facilitate a gradual shift towards internal circulation. Evidently, China's rebalancing has since started but at an incremental pace. On the external front, net exports no longer contribute that much to China's growth, with its current account surplus narrowing significantly from $10 \%$ of GDP in 2007 to $0.4 \%$ in 2018. On the domestic front, consumption has contributed more to GDP growth than investment since 2011, as the service sector's share in China's economy has risen steadily in the past decade to $52 \%$ of total output. According to official data, the share of China's consumption in GDP rose from $48 \%$ in 2010 to $58 \%$ in 2019 .

To further tap domestic market potential, creating a unified and open domestic market is essential. Regional development strategies can help to eliminate market barriers to ensure "domestic circulation" and strengthen domestic demand. The government's regional development strategy has shifted to focus more on promoting mega-clusters to increase urbanization, employment and consequently domestic consumption (Morgan Stanley, 2019). This is distinct from past regional rebalancing initiatives (including Western Region Development since 2000 and Northeast Revitalization since 2004), which were mainly aimed at reducing regional income gaps and relieving pressure from population flows to developed coastal regions. In the future, central China is likely to see larger gains in urban population compared to other regions, as migrants move from the rural parts of central China to large centers, such as Zhengzhou (Henan), Wuhan (Hubei) and Changsha (Hunan). In addition, while China's agricultural productivity is currently less than a tenth of the level in developed economies due to fragmented land usage, land reforms ${ }^{6}$ and the wider adoption of smart farming ${ }^{7}$ should boost rural labor productivity and entice more workers to migrate

6. Land reforms hold the key to boosting large-scale farming and freeing up more of the rural population for urbanization. Since December 2014, China has launched piloting reforms to separate farmland ownership, contract rights and operating rights, which make it possible for farms to collect scattered land for large-scale planting. In August 2019, China's top legislature also adopted a revision to the land administration law, which gives farmers more property rights, enhances the protection of basic arable land, extends the duration of existing farmland use contracts by another 30 years upon expiry and improves the transparency of rural land requisition.

7. Since 2014, policymakers have focused on promoting smart farming based on advanced technologies, such as IoT (Internet of Things), cloud computing, big data analytics and automation, to increase the quality and quantity of agricultural products. 
to cities (coupled with hukou reforms), boosting urbanization and domestic consumption.

The government's regional development strategy to prioritize integrated areas and promote internal connectivity has notably led to the development of integrated clusters, such as the Guangdong-Hong Kong-Macau Greater Bay Area (GBA), Jing-Jin-Ji, YREB and the ChengduChongqing (Cheng-Yu) economic region. The development of the $\mathrm{GBA}^{8}$ is prioritized among all regions owing to its strong industrial base and diversified economy. It is expected to build on the success of industrial clusters in the Pearl River Delta (PRD) to become an important regional engine for Chinese economy in the coming years, while the YREB aims to promote growth by unifying the more centrally located industrial bases with those of Shanghai, Jiangsu and Zhejiang. To accelerate internal rebalancing, the Beijing-Tianjin-Hebei region has been granted strong policy support and attracted government investment, but it will face challenges in attracting private investor interest.

Among the mega-clusters, the YRD has been chosen to lead China's "dual circulation" pattern of development. Earmarked as a national development priority, it is set to play an important role in the dual circulation strategy first mentioned at a politburo meeting in May 2020 (Tang, 2020). In December 2019, the State Council issued an outline of the integrated regional development of the YRD aimed at achieving urban-rural integration within the region and integrated development of high-tech industries, infrastructure, ecological environment and public services by 2025 . This is in line with the dual circulation strategy of enhancing domestic consumption and promoting indigenous innovation to prepare China for the next stage of economic development. In the plan, the government sets 2025 as the year to have at least $80 \%$ of the YRD region covered with the 5th generation $(5 \mathrm{G})$ mobile networks and an increase in urbanization rate to $70 \%$ and to attain a ratio of R\&D expenditure to GDP in the region of 3\% from 2.8\% in 2019 (Xinhua News Agency, 2019).

To facilitate regional integration, some policy measures and development initiatives have been adopted to improve business environment and economic efficiency. Since December 2019, the State Taxation Administration has taken the lead to boost tax efficiency for YRD integration by rolling out measures to optimize regional tax services, such as facilitating cross-provincial tax service, compiling unified lists of tax-related matters and realizing taxpayer information sharing among local tax bureaus (Zhang, 2020). In September 2020, Shanghai and three other provinces released the Agreement on Mutual Recognition and Application of Electronic Certificates in the YRD Region in a move to facilitate the cross-provincial recognition on electronic certificates, such as business and driver's licenses, citizen's ID cards and qualification certifications of road transport practitioners. This is expected to facilitate the easy movement and growth of businesses, entrepreneurs and workforce in the region.

To support domestic demand and innovation, the State Council's plan to integrate the YRD further proposed a "digital YRD region" with new information infrastructure, or "new infrastructure". Advances in technological innovation will be applied to support industry and facilitate technology transfers. Shanghai is reportedly ramping up the construction of 5G networks and data centers. In August 2020, Shanghai established the Lingang Xinqiao Emerging Industrial Park in the Lingang New Area of the Shanghai Free Trade Zone (FTZ). At the opening ceremony, the industrial park signed the first batch of around twenty international digital economy industry 
projects (Zhang, 2020).

Furthermore, China's 14th Five-Year Plan (2021-2025) has also included the GBA as part of the national strategy to develop China's economy and growth. As one of the more developed megaregions in China, the cities in GBA are well linked and connected given the high-speed railway, the Hong Kong-Zhuhai-Macau sea bridge and other forms of physical infrastructure. To make the GBA more competitive as an international logistics hub, infrastructure upgrade to increase the connectivity of the region is already underway, including more than ten high-speed rail and intercity rail lines, four bridges crossing the Pearl River and new airports and runways in the pipeline (Ernst \& Young, 2019). Other new infrastructure projects are also being constructed or in the pipeline in various GBA cities (Appendix 1).

Underpinned by the "dual circulation" strategy and partly driven by the need to align Hong Kong closer to the mainland economically, as well as socially, Beijing has implemented a raft of initiatives to promote further regional integration in the GBA region, which include fostering cooperation between Hong Kong and Shenzhen in innovation and technology research, as well as strengthening intellectual property (IP) protection. Beijing further issued the "Opinions Concerning Financial Support for the Establishment of the GBA" in May 2020, supporting the deepening access between Hong Kong and the financial markets in the mainland. The state-driven plan could provide an impetus to the further integration of GBA towards greater financial connectivity of infrastructure and markets across Guangdong, Hong Kong and Macau. ${ }^{9}$ This has led to measures to enable the crossborder transfer of assets and investment in private equity funds, further develop the offshore RMB market and establish the GBA as a center for green and sustainable finance in order to strengthen the interconnectivity between cities and facilitate the development of financial services in the GBA.

In view of the changing global context, a crucial element of the dual circulation strategy is opening up to international trade to increase the competitiveness of the region. "Domestic or internal circulation" needs to be complemented with further engagement with "external circulation", or opening up to the outside world. The signing of the RCEP, or Regional Comprehensive Economic Partnership, with ASEAN countries, for instance, is a manifestation of the "external circulation" for China in maintaining trade linkages with its regional neighbors. Engaging in trade with the outside world would increase the impetus for China to further deepen its structural economic reforms and improve industrial competitiveness. A key project within the YRD is the Lingang New Area of the Shanghai FTZ, which was built in order to boost the development of Shanghai as an international financial center and improve the business environment to attract more multinational corporate headquarters and global talent. New policies introduced in the Shanghai FTZ aimed to streamline administrative procedures and promote further competition by further opening up its financial sector. Pilot schemes on finance are being rolled out in the Lingang New Area, with MNCs being encouraged to set up global or regional fund management centers in Shanghai, as well as local and cross-border financing opportunities. These policy initiatives are part of the efforts by the authorities to implement structural domestic reforms to integrate with the world and increase China's international competitiveness.

9. The opinions put forward 26 detailed measures across five areas: promoting cross-border trade and investment and providing seamless delivery of financial services in the GBA, continued opening up of the financial services sector, promoting the integration of financial markets and financial infrastructure, increasing innovation in the financial services industry in the GBA, and effectively managing cross-border financial risks. 


\section{Issues and challenges}

With varying levels of development, regions could specialize and gain from enhanced linkages with other regions/areas. There is much to be gained for enhancing the extent to which existing economic clusters are connected so that cities or provinces can specialize, trade goods and services within the cluster and develop economies of scale. Such localization and intra-cluster linkages can enhance overall efficiency and productivity. In the case of the YREB, research by the World Bank indicates a low degree of economic integration among cities in the upper, middle and lower reaches of the region (World Bank and the PRC's Development Research Centre of the State Council, 2019). Much of the trade in the region takes place within the province as opposed to between provinces, thus missing out on opportunities to leverage the regional market and interprovincial trade. As such, to benefit from spatial development, there is a need to enhance trade and linkages across the YREB via increased infrastructure investment and spatially targeted fiscal policies to support market integration and industrial upgrading of these regions.

While regional-coordinated development could be better supported when markets are open, too often, regional cooperation is constrained by intergovernmental fiscal arrangements and performance assessment systems of local government officials, which tend to encourage local protectionism and market segmentation (HSBC, 2019). Local governments are strongly incentivized to focus on developing their local economies with biased industrial policies, including imposing a variety of barriers to inter-provincial trade in order to protect domestic enterprises and local tax revenue. Under such an institutional environment, regions tend to focus on competition instead of cooperation, hence limiting inter-provincial economic integration. In the Yangtze River Delta, for instance, the division of labor between government intervention and market mechanism has not been clearly spelled out by the authorities. Currently, administrative intervention is the main mechanism for regional collaboration in the YRD. Small leading groups have been established by central and local governments to facilitate collaboration in investment and industrial development when the market mechanism is known to be more efficient in allocating resources to support collaboration and encourage division of labor. Instead, the provinces (Shanghai, Zhejiang, Jiangsu and Anhui) in the YRD region all directed their efforts at the same high-tech and high value-added industries, such as artificial intelligence, semiconductor and biomedical industries. This tends to lead to resource wastage and is likely to hinder the urban clusters from reaping benefits from agglomeration economies of scale.

Among the mega- or regional clusters, although the infrastructure in the GBA is the most developed given the region's favorable geographical location, inter-city competition for regional dominance is one of its biggest drawbacks. Inter-city rivalries among the core cities of Hong Kong, Guangzhou and Shenzhen are challenges to the GBA's further economic development and the region's integration initiative. This is in addition to the differences in political, legal, social and economic governance systems under different administrative regions of the nine participating cities within Guangdong, Hong Kong and Macau. Compared to other famous bay areas in the world, such as the Greater Tokyo or San Francisco Bay Area, the GBA has the most complex governance structure. Underlying the fragmented nature of the mega-city regions, Guangdong, Hong Kong and Macau have separate political systems and custom zones with different institutional, legal and tax collection systems, as well as different currencies. This implies that business enterprises operating 
in the GBA will have to follow different regulatory regimes, rendering high compliance costs, which could adversely impact business efficiency and hinder regional integration efforts.

The challenges faced by the authorities in promoting cross-border regional integration underscore the importance of financial connectivity to complement with physical infrastructure in order to facilitate efficient flow of capital. Theoretically, Hong Kong, being the financial hub of China and the Asia region, could complement other GBA cities, such as Shenzhen and Guangdong, given that these cities are diverse in terms of economic specialization and regional patterns, but as every city government in the GBA has its own interest, agenda and development strategy for boosting financial and economic development, this will complicate the pursuit of inter-regional policy coordination that is essential for achieving regional economic integration within the GBA. Rather than providing a major impetus for boosting national development, efforts to promote an integrated city-cluster in the GBA could be derailed.

Inter-city competition for high-tech industrial sectors has resulted in wasted investment and low productivity growth in the YRD. Local governments have no incentive to collaborate with one another and there are no clear mechanisms to support regional integration. Further, there is a lack of coherent interaction between firms, universities and research institutes in technology innovation - a potential constraint on the future development of the YRD. Similarly, weak interregional industrial collaboration is a factor in the limited development of the Beijing-TianjinHebei (BTH) region despite its infrastructure readiness. Although political backing from the central government has endowed the Xiong'an New Area (XNA), which is sited in central Hebei, with a vast transport network, such as the inter-city railway linking Beijing and Xiong'an, these top-down initiatives, which are mainly driven by the central government, have their drawbacks. Thus far, the XNA is not able to fulfill its mission of being the development hub to drive the growth of the region encompassing Beijing, Tianjin and Hebei. With the central government's support, many resources have been channeled to facilitate the development of the XNA in order to ameliorate the uneven economic development of the BTH region, but this could create intense competition for resources and talent between the XNA and its surrounding cities, as well as with Beijing and Tianjin. Measures to support innovation and adopt smart technology in the XNA have been proposed by the government but there are potential limitations to the XNA's ability to attract sufficient talent, as it does not enjoy close proximity to top universities, unlike Beijing. The XNA's over-reliance on policy support from the central government is also likely to hamper its ability as a functioning city to support Hebei and Beijing, since most investors would be wary of strong government intervention with weak private initiative.

The feature of inter-city competition in industrial development and attracting foreign investment is common also in the Chengdu-Chongqing Economic Circle (CCEC). Designated as hubs of Western China, Chengdu and Chongqing are designed to be the economic growth engine for Western China, which has been continuously hampered by inadequate infrastructure for many years. The CCEC initiative requires the local governments to cooperate in various aspects, such as building mutually beneficial transportation and logistics network to support market activities and further support industrial and regional co-development. Since March 2020, Chengdu and Chongqing have signed cooperation agreements and initiated infrastructure construction, such as building regional highways and regulating environmental issues. As Chongqing and Chengdu upgraded their local transportation and economic cooperation, the CCEC region is expected to become a gateway 
for international trade in Western China. The China-Europe Railway Express, an important part of the BRI, is shipping products made in China's western provinces to Central Asia and further to Europe. Trains start from both Chongqing and Chengdu on this line and are expected to enhance infrastructural connectivity and bring economic benefits to Western China. Through the CCEC strategy, Chinese cities including Chongqing and Chengdu will have more trade opportunities with Europe and Central and Southeast Asia. However, the two governments of Chongqing and Chengdu have yet to provide concrete policies to avoid competition in economic development, even though some special zones are planned between the two cities to work on building industrial clusters and strengthening research and innovation.

\section{Conclusion}

China's economy is facing both severe internal and external challenges. Apart from tepid global demand, it is also encountering anti-globalization sentiments, particularly from the West, which has prompted many multinational firms to restructure their supply chains and implement the "China +1 " strategy in light of the US-China trade war. A rising number of countries have shifted their firms back home or out of China, jeopardizing China's status as the "factory of the world". In response, China is shifting to the "dual circulation" strategy to strengthen the resilience of its economy and focus on its domestic market and indigenous technological innovation in its drive to sustain national economic growth. The core thinking behind dual circulation however is not new. Over the past decade or so, China has been rebalancing its economy away from an export-led trajectory towards one that is propelled more by domestic consumption. What the US-China trade war and the current viral pandemic have done is add momentum to the process of enhancing domestic demand as a key driver to support economic growth.

The emphasis of the "dual circulation" development paradigm has important implications for China's regional dynamics and regional economic development. Since 2013, China has planned several major city clusters or integrated mega-clusters to boost domestic demand and drive economic growth. These major clusters comprise the Guangdong-Hong Kong-Macau Greater Bay Area (GBA), YRD, Jing-Jin-Ji (Beijing-Tianjin-Hebei) Region, Xiong'an New Area, ChengduChongqing Economic Circle (CCEC), Western Region Development and the Northeast Region Revitalization. Leveraging on the well-developed infrastructure network, the Chinese government is expected to transform the GBA and YRD into economically integrated regions with an efficient flow of capital among the cities.

As a crucial part of China's economic transition, China should move towards a new stage of reforms designed to help rebalance its economy by facilitating private initiative and enterprise and innovation to increase productivity. It has established an astonishing network of hard infrastructure, such as roads, power stations and communication networks, but this must be complemented by "soft" infrastructure investment, such as establishing the institutional frameworks and regulations, in order to support sustained economic and social progress. Policies to promote regional development must include fiscal or monetary policies that remove distortions in the factor markets (for instance, channeling savings and resources to productive uses, fair tax system, etc.). This is particularly important in promoting coordinated regional development among the major cities and integrated clusters. 
Similarly, reforms on social welfare, ${ }^{10}$ education and even hukou or household registration policies that previously distorted the labor market and inhibit the cross-border flow of workers among regions are vital. Additional reforms, such as land reform, are also essential to support domestic consumption under the dual circulation strategy. Rural households have a significant percentage of their wealth locked in land use rights (which are collectively owned), which still face onerous restrictions in terms of transfer and in effect limit the mobility of rural households. Further reforms to integrate both urban and rural land markets and allow market forces to play a larger role in the determination of prices and the distribution of land rights will create efficiencies through the redistribution of wealth to rural households, as well as help increase urban-rural mobility. ${ }^{11}$

As many policies are determined at the local level, streamlining policies at a broader regional level would allow greater mobility for urban workers, increase urbanization and domestic consumption and allow for overall increased efficiency gains from enhanced integration of regional clusters. Successful regional integration requires better infrastructure, deregulation of factor markets and coordination among local governments. This will go a long way in ensuring that China's interregional growth and development will be sustainable and balanced in the long term.

\section{References}

Chan S (2020). "China's evolving role in regional production networks: Evidence from the ICT industry". Journal of Southeast Asian Economies, 37(1): 78-92.

Deloitte (2019). Rising Innovation in China: China Innovation Ecosystem Development Report 2019. Beijing, China: Deloitte. https://www2.deloitte.com/cn/en/pages/innovation/articles/china-innovation-ecosystemdevelopment-report-20191.html

Ernst \& Young (2019). Guangdong-Hong Kong-Macau Greater Bay Area: From Connectivity to Integration. Beijing, China: Ernst \& Young.

Henderson V (2003). "The urbanization process and economic growth: The so-what question". Journal of Economic Growth, 8(1): 47-71.

HSBC (2019, May 27). China Aims to Supercharge Economy with the Greater Bay Area. Dubai, United Arab Emirates: HSBC.

(2020a, September). China Insights: A New Agenda in the Making. Vancouver, Canada: HSBC.

(2020b, October 19). China's New Five-Year Plan: One Growth Engine Is Not Enough. London, UK: HSBC.

KPMG (2020, May 21). Analysis of New Measures for GBA Financial Support. Beijing, China: KPMG. https:// home.kpmg/cn/en/home/insights/2020/05/interpretation-of-the-opinions-concerning-financial-support-forthe-establishment-of-the-guangdong-hong-kong-macao-greater-bay-area.html

McKinsey Global Institute (2019, July). China and the World Economy: Inside the Dynamics of a Changing Relationship. McKinsey Global Institute.

Moody's Analytics (2019, January) China's Provincial Economies: Growing Together or Pulling Apart? New York, NY, USA: Moody's Analytics.

10. For instance, social insurance across cities is not portable. This represents a thorny issue, as many workers would have difficulties claiming social insurance benefits after relocating to another city in the region.

11. Currently, rural land must first be acquired by the government to be converted to land for construction. This presents inefficiencies. Land prices offered by the government are often lower than those on the open market, effectively providing less monetary benefits to rural collective land owners. Further reform is needed to allow for more market-driven dynamics in the determination of land prices, which would help provide larger returns for rural collective land owners. Additional streamlining of the approval process, which still has a complex structure requiring multiple layers of consent to convert rural land to construction land, will also help make land-use transfers more efficient (see HSBC (2020b)). 
Morgan Stanley (2019, November 7). "The rise of China's supercities: New era of urbanization”. MorganStanley. com.au. https://www.morganstanley.com.au/ideas/2019-supercities

Tang F (2020, August 24). "China to use Yangtze River Delta to showcase 'dual circulation' economic strategy". South China Morning Post.

Wong J (2016). Zhu Rongji and China 's Economic Take-Off. London, UK: Imperial College Press.

World Bank (2020). "From recovery to rebalancing: China's economy in 2021". China Economic Update December 2020. Washington, DC, USA: World Bank.

World Bank and the PRC's Development Research Centre of the State Council (2020). Innovative China: New Drivers of Growth. Washington, DC, USA and Beijing, China: World Bank and the PRC's Development Research Centre of the State Council.

Xinhua News Agency (2019, December 1). The Central Committee of the Communist Party of China and the State Council issued the 'Outline of the Yangtze River Delta Regional Integration Development Plan' (in Chinese). Xinhua News Agency. http://www.gov.cn/zhengce/2019-12/01/content_5457442.htm

Zhang Z (2020, September 17). "What does the Yangtze River Delta integration mean for businesses in China". China Briefing. https://www.china-briefing.com/news/yangtze-river-delta-integration-opportunitiesincentives-for-businesses-in-china-dual-circulation-strategy/ 
Appendix 1. List of major infrastructure development projects in the GBA

\begin{tabular}{|c|c|c|}
\hline City & Infrastructure Projects & Project Description \\
\hline \multirow{6}{*}{ Guangzhou } & Baiyun Airport & $\begin{array}{l}\text { Expansion of a new terminal and two additional runways to } \\
\text { become a business aviation service base }\end{array}$ \\
\hline & Zhengguo Airport & Construction of a second civil airport began in 2020 \\
\hline & Nansha Port & $\begin{array}{l}\text { The third and fourth phases of development and the first } \\
\text { phase of Nansha cruise terminal }\end{array}$ \\
\hline & Intercity Railway & $\begin{array}{l}\text { Expansion to loop in Foshan, Jiangmen, Qingyuan and } \\
\text { Zhuhai }\end{array}$ \\
\hline & Railway & Guangzhou-Shantou high-speed railway \\
\hline & Highway & $\begin{array}{l}\text { Expansion of Shenyang-Haikou and Beijing-Hong Kong- } \\
\text { Macau Expressway }\end{array}$ \\
\hline \multirow{4}{*}{ Shenzhen } & Tramline & Construction of Tramline No. 3 in Longgang \\
\hline & Highway & Expansion of Shenzhen-Huizhou highway \\
\hline & Railway & Construction of railway to Maoming and Ganzhou, Jiangxi \\
\hline & Shenzhen-Zhongshan Bridge & Shenzhen-Zhongshan bridge scheduled to open in 2024 \\
\hline Foshan & Pearl River Delta New Line Airport & $\begin{array}{l}\text { Construction of new airport in preparation as part of " } 5+4 \text { " } \\
\text { airport in Guangdong }\end{array}$ \\
\hline \multirow{2}{*}{ Jiangmen } & Highway & $\begin{array}{l}\text { Jiangmen section of Guangzhou-Zhongshan-Jiangmen } \\
\text { highway and Zhongshan-Kaiping highway }\end{array}$ \\
\hline & Intercity Railway & Jiangmen section of Shenzhen-Jiangmen-Maoming railway \\
\hline \multirow[t]{2}{*}{ Huizhou } & Pingtan Airport & $\begin{array}{l}\text { Expansion of airport to accommodate civil flights and cargo } \\
\text { as part of " } 5+4 \text { " airport in Guangdong }\end{array}$ \\
\hline & Highway & Huizhou section of Hunan-Huizhou highway \\
\hline Zhongshan & Highway & $\begin{array}{l}\text { Zhongshan-Kaiping highway and Zhongshan-Jiangmen } \\
\text { highway }\end{array}$ \\
\hline \multirow[b]{2}{*}{ Zhuhai } & Intercity Railway & Guangzhou-Foshan-Jiangmen-Zhuhai intercity railway \\
\hline & Jinwan Airport & $\begin{array}{l}\text { Construction of new highway and terminal in preparation as } \\
\text { part of " } 5+4 \text { " airport in Guangdong }\end{array}$ \\
\hline \multirow{2}{*}{ Zhaoqing } & Highspeed Railway & Construction of Shenzhen-Zhaoqing high-speed railway \\
\hline & Railway & Construction of railway to Nanhai and Liuzhou, Guangxi \\
\hline \multirow[t]{2}{*}{ Dongguan } & Bridge & The 2nd Humen bridge put in operation in 2019 \\
\hline & Intercity Railway & $\begin{array}{l}\text { Guangzhou-Dongguan-Shenzhen intercity railway, } \\
\text { Dongguan-Huizhou intercity railway, Foshan-Dongguan } \\
\text { intercity railway, Zhongshan-Humen-Longgang intercity } \\
\text { railway and Dongguan-Shenzhen rapid transit }\end{array}$ \\
\hline \multirow[t]{2}{*}{ Macau } & Border crossing & $\begin{array}{l}\text { Construction of new crossing adjacent to the existing } \\
\text { checkpoint at Gongbei to expand passenger capacity }\end{array}$ \\
\hline & Hong Kong-Zhuhai-Macau Bridge & Opened in October 2018 \\
\hline \multirow[b]{2}{*}{ Hong Kong } & Airport & Construction of the third runway \\
\hline & $\begin{array}{l}\text { Guangzhou-Shenzhen-Hong Kong } \\
\text { Express Rail Link }\end{array}$ & Opened in September 2018 \\
\hline
\end{tabular}

Source: Ernst \& Young, 2019 